\title{
Joinville como Fonte de Economias Externas às Empresas Atendidas pelo Programa ALI ${ }^{1}$
}

\author{
Joinville as a source of external economies to the companies served by the ALI \\ Program
}

\author{
Stéfanie Bilicki \\ stefaniebilicki.alisc@gmail.com \\ Universidade Federal do Paraná (UFPR) \\ Pablo Felipe Bittencourt \\ pablofelipe.bittencourt@gmail.com \\ Universidade Federal de Santa Catarina (UFSC)
}

Resumo: Percebendo o contexto econômico e político em que estão inseridas, as MPEs precisam buscar diferenciação por meio de ações inovadoras. Para tanto, é necessário acessar as informações disponíveis, tanto do ambiente interno quanto do externo, e aproveitar-se das externalidades. Este estudo, mediante método descritivo exploratório, faz uma análise dos resultados obtidos na dimensão Ambiência Inovadora, que procura mensurar as ações empresariais na busca por conhecimento e analisar o impacto dessas ações nas outras dimensões do Radar de Inovação, sendo o radar uma metodologia utilizada pelo Programa ALI - Sebrae/CNPq. A pesquisa foi realizada com os dados de 20 empresas atendidas pelo programa em Joinville/SC, de novembro de 2015 a agosto de 2017, e os resultados, exemplificados por dois casos, apontam para a importância de ações orientadas a aproveitar o conhecimento disponível. Nesse sentido, uma transformação das rotinas da empresa, em prol de uma cultura de inovação, mais voltada para a busca de conhecimentos externos complementares aos internos, parece ser um dos maiores resultados da política do Sebrae.

Palavras-Chave: Ambiência Inovadora; Economias Externas; Programa ALI; Conhecimento; Inovação

\begin{abstract}
Considering the economic and political context in which brazilian firms are inserted, it is necessary to seek differentiation through innovative actions. In order to do this, the company must access available information, both from the internal and external environment, to take advantage of externalities. Therefore, this study, through an exploratory descriptive method, proceeds to an analysis of the results obtained in the innovative ambience dimension, which seeks to measure the entrepreneurial actions in the search for knowledge and to analyze the impact of these actions on the other dimensions of the innovation radar, which is a methodology used by the Program ALI - Sebrae / CNPq. The research was carried out with data from 20 companies served by the program in Joinville / SC, from November 2015 to August 2017, and the results, exemplified by two cases, point to the importance of actions oriented to take advantage of the available knowledge. In this sense, a transformation of the firm's routines, in favor of a culture of innovation, more focused on the search of external knowledge complementary to internal ones, seems to be one of the major results of the Sebrae policy.
\end{abstract}

Keywords: Innovative Environment, External Economies, ALI Program, Knowledge, Innovation.

Recebido em: 07-01-2019. Aceito em: 08-03-2019.

${ }^{1}$ Os autores agradecem ao SEBRAE-SC a liberação do artigo para publicação. 


\section{INTRODUÇÃO}

O atual cenário econômico brasileiro é crítico, segundo o IBGE (2017), em 2015 e 2016, a queda do Produto Interno Bruto (PIB) foi superior a 7\%, configurando a maior crise da história, o que gerou taxa de desemprego próxima a 14\%. Evidentemente, muitas micro e pequenas empresas foram desoladas por essa situação.

Em contextos como esses, instituições de apoio como o Sebrae (Serviço Brasileiro de Apoio às Micro e Pequenas Empresas), com projetos como o Programa ALI (Agente Local de Inovação) podem ser decisivas. Pois, compreendendo a inércia das pequenas empresas, o programa tem por objetivo levar pessoal treinado - os agentes locais de inovação - e capacitado até as pequenas empresas, a fim de diagnosticar dificuldades de gestão e oportunidades de inovação, apresentando melhorias personalizadas aos problemas enfrentado, além de ideias e ações inovadoras que melhorem os resultados da empresa.

No entanto, poucas empresas são ativas na busca pelos recursos disponíveis no ambiente em que estão inseridas, tendo dificuldade até de explorar os recursos disponibilizados pelas instituições presentes no cenário em que atuam, mesmo quando o contexto geográfico favorece.

Não obstante, o contexto regional/local tem sido objeto da análise especialmente desde que Alfred Marshall destacou o papel das economias geradas pela proximidade geográfica. Nesse sentido, estudos mais recentes na linha de economia da inovação têm reforçado o papel das economias externas. Giuliani (2005), por exemplo, defendeu que aglomerações produtivas caracterizadas por empresas com forte base de conhecimento são mais propensas a revelar trocas intensas de conhecimentos intracluster, o que denotaria alta conectividade, ou seja, alto nível de aproveitamento de externalidades locacionais. De fato, diversos outros estudos já foram realizados, sobretudo em países desenvolvidos, como o de Spithoven et. al. (2010), que estudaram como novas instituições têm ajudado pequenas empresas de setores tradicionais de um país altamente desenvolvido (Bélgica) a absorverem novas tecnologias. Ocorre que, em geral, a maior parte dos estudos trata de MPEs de setores de alta intensidade tecnológica (OCDE, 2003), em especial do setor de software, ou são estudos relacionados à absorção tecnológica (de produto e processo) em relação às tecnologias da atual revolução (PEREZ, 2004). Tais estudos, ainda que focados em micro e pequenas empresas, fogem do escopo do presente artigo. Aqui as empresas são de porte muito reduzido, de faturamento entre $\mathrm{R} \$ 360$ mil e R\$ 3,6 milhões anuais; a maioria tem entre 7 e 12 empregados. A menor tem apenas dois empregados e a maior, 36. Os ramos de atividade 
em que atuam são muito tradicionais, tais como panificação, metalurgia, bares, lanchonetes, restaurantes, materiais de construção, comércio, automação, etc.

O objetivo do artigo é apresentar evidências do valor para esse tipo de empresas de absorver conhecimentos externos disponíveis em uma cidade de grandes dimensões. Como esse não é exatamente o objeto de pesquisa de trabalhos que utilizam o tradicional conceito de "capacidade de absorção" (COHEN e LEVINTHAL, 1990 e ZAARA e GEORGE, 2002), apoiamo-nos na metodologia do Radar de Inovação (BACHMANN, 2008), especialmente no que se refere à dimensão analítica da "Ambiência Inovadora", formulada para captar elementos intramuros desse tipo de firma, os quais, além de importantes à realização direta de inovações, também atuariam na causa da busca de informações externas relevantes, tais como universidades, centros de capacitação e clientes, todas contempladas na metodologia do Radar de Inovação.

Para tanto, foram analisadas 20 pequenas empresas de diversos segmentos atendidas pelo Programa ALI na Região Norte de Joinville. Ao final, pode-se avaliar, por meio de exemplos, como uma ambiência inovadora interna adequada, associada a um ambiente externo promissor, pode melhorar a capacidade inovadora da empresa, o que corrobora a posição de Choo (2003, p. 28), quando destaca que "novos conhecimentos permitem à organização desenvolver novas capacidades, criar novos produtos e serviços, aperfeiçoar os já existentes e melhorar seus processos organizacionais".

O artigo contém 4 seções, além desta introdução. São elas, respectivamente: referencial teórico, metodologia, análise de dados e casos e conclusão. Na sequência, apresentam-se os temas: externalidades, conhecimento e inovação, mas também se contextualizam algumas oportunidades percebidas na cidade de Joinville derivada da atuação da autora do artigo no Programa ALI. A metodologia é apresentada logo depois. A análise dos dados utiliza gráficos e antecede a complementar apresentação de dois casos que exemplificam os resultados alcançados. As conclusões sugerem que as empresas atendidas pelo Programa ALI receberam importante suporte e conhecimento do ambiente em que estão inseridas. Para tanto, foi necessário criar ações que as fizessem perceber esse potencial outrora não aproveitado, justamente por não explorarem o conhecimento que está ao seu alcance.

\section{INOVAÇÃO, EXTERNALIDADES LOCACIONAIS E O PROGRAMA DE APOIO DO SEBRAE-SC}


Esta seção está subdividida em outras três. De início, os conceitos de externalidades locacionais para absorção de conhecimentos e geração de inovações são apresentados como parte mais relevante do referencial teórico. A seguir, apresentamos espaço local onde acontecem as interações, o município de Joinville. A seção é complementada por uma apresentação do Programa ALI (Agentes Locais de Inovação) do Sebrae-SC, que serve de estímulo à intensificação da atividade inovadora nas rotinas das empresas desse porte.

Antes de tudo, é preciso ponderar que o objeto deste artigo é pouco usual à tradicional literatura sobre inovação, notadamente de cunho neoschumpeteriano, a qual já conseguiu demonstrar empiricamente a formação de grandes ciclos de desenvolvimento mundiais, explicados pela capacidade de determinadas sociedades de produzirem grandes inovações e das demais, de absorvê-las (FREEMAN, SOETE, 2008; PEREZ, 1989 e ROSENBERG, 2006). Essa literatura está baseada em setores industriais modernos e nos impactos modernizantes a outros setores industriais. Daí emergiu o valor de pesquisar os processos típicos de inovação de diferentes países e regiões, o que desembocou, por exemplo, no conceito síntese de Sistemas de Inovação (BITTENCOURT; CÁRIO, 2017). As inovações que iremos analisar a seguir podem ser vistas como reflexo de um contexto em que inovação se tornou rotina (NELSON; WINTER, 2005) e que deriva dos ditos ciclos longos ou ondas longas (PEREZ, 2003). Contudo, é preciso destacar que, apesar de se tratar de fenômeno relacionado, o processo de inovação nas pequenas empresas (objeto do presente artigo) não foi o objeto de análise de Schumpeter, nem mesmo costuma ser o de autores neoschumpeterianos (os que procuram avançar na linha de pensamento de Schumpeter), porque as inovações nesse segmento não causam o impacto potencial relevante aos sistemas econômicos.

As firmas aqui analisadas estão na ponta das revoluções, são as últimas a serem impactadas e apenas sofrem sua influência, o que não significa que todas sofram tal influência da mesma forma. Daí o objetivo de investigar a absorção de conhecimentos derivada das economias externas presentes em um determinado contexto (Joinville-SC, no nosso caso).

\section{EXTERNALIDADE, CONHECIMENTO E INOVAÇÃO EM EMPRESAS DE PEQUENO PORTE}

Informação é recurso-chave nas organizações. Os agentes econômicos estão sempre fazendo escolhas orientadas pelo que sabem. Para o princípio econômico neoclássico da racionalidade substantiva (maximizadora), os agentes detêm todas as informações de que 
precisam. Porém, no mundo real, as informações não estão sempre disponíveis, e mesmo estando, as capacidades para reconhecê-las são limitadas (SIMON, 1976). Isso porque os seres humanos são algo mais que razão; há sempre um complexo arranjo de fatores influenciando a tomada de decisão.

Dessa forma, já que as informações não estão sempre disponíveis, é necessário buscálas, isto é, colocá-las à sua disposição. É isso que permite tomar a decisão mais acertada possível, tornando assim o cenário mais previsível, os riscos menores e, por conseguinte, os custos menores também. Isso porque erros ou ineficiências empresariais custam dinheiro, acarretando baixa capacidade competitiva.

Destarte, compreender as informações que geram conhecimento como ativo estratégico implica também melhorar a comunicação interna e externa. Sabe-se que muito conhecimento é gerado quando se reúnem grupos de interesses para trocar ideias e saberes - é o caso de congressos, feiras, palestras e cursos. O ambiente tem um importante papel neste sentido, pois em cidades onde há presença de instituições organizadas para fornecer conhecimento técnico e especializado há maior cooperação e interação interfirmas. Por essa razão, a diversificação industrial de grandes cidades costuma gerar fontes diversas de informação, que podem ser aproveitadas pelas empresas para melhorar seus processos de inovação. Trata-se de se aproveitar de "economias externas" à firma, ou seja, as externalidades (BITTENCOURT, et. al, 2017).

Sobre as economias externas, segundo Garcia, 2006, Marshall foi pioneiro em constatar que "a presença concentrada de firmas em uma mesma região pode prover ao conjunto dos produtores vantagens competitivas, que não seriam verificadas se eles estivessem atuando isoladamente". Essas vantagens estão relacionadas "aos ganhos de organização e desenvolvimento decorrentes da maior integração entre os agentes". Entre as vantagens elencadas por Marshall estão a presença de mão de obra qualificada, de fornecedores especializados em bens e serviços e dos transbordamentos tecnológicos e de conhecimento (GARCIA, 2006).

A essa abordagem, Porter, ao utilizar conceitos presentes em outros trabalhos, “incorpora a importância das relações de cooperação com fornecedores de insumos especializados como um dos elementos capazes de fortalecer a capacidade competitiva das empresas" (GARCIA, 2006, p. 314). Esse é um dos vértices do bastante conhecido "diamante de Porter". 
Já Krugman leva o debate das economias externas à configuração do cenário internacional e destaca os "retornos crescentes de escala" como uma força centrípeta das aglomerações, capaz de superar a teoria anterior das vantagens comparativas, o que trouxe um destaque importante para o estudo das aglomerações empresariais e suas externalidades. Portanto, as empresas são atraídas para concentrações empresariais, pois conseguem se apropriar de economias externas que trazem vantagens competitivas (GARCIA, 2006).

Garcia (2006, p. 307) ainda pontua que as economias externas podem ser aproveitadas pelos agentes mediante a "construção de canais próprios de comunicação e de fontes específicas de informação, já que a proximidade geográfica entre os produtores aglomerados facilita a circulação de informações e conhecimentos", além de "contribuir para o desenvolvimento de novas capacidades organizacionais e tecnológicas, o que leva ao fomento de um processo de aprendizado de caráter local”. Essa interação, portanto, pode proporcionar soluções para os problemas enfrentados pelas empresas.

E, conforme estudo de Mendéz (2007), “a simples concentração geográfica, associada à presença de clusters localizados, já gera certo volume de economias externas, que podem ser aproveitadas de forma passiva pelas empresas ali localizadas”. Claro que as vantagens são maiores se as empresas aproveitam ativamente desse ambiente, criando relacionamentos de confiança, pois "a transmissão de conhecimento tácito e não formalizado é aquela que fomenta a colaboração em ações conjuntas e, por meio delas, o aprendizado coletivo, tornando-se assim fontes de vantagens competitivas dinâmicas, que permitem falar de uma verdadeira eficiência coletiva". Dessa forma, é também necessário "transcender a esfera estritamente econômica para enfocar na possível existência de redes de apoio social e institucional".

Aproveitar-se ativamente do ambiente não como algo derivado apenas da vontade de um ou mais atores. É preciso ter capacidade de diálogo, de troca de experiências, de conhecimentos. Daí que o acúmulo interno de conhecimentos seja essencial à capacidade de absorção externa, como observaram primeiramente Cohen e Levinthal (1990). Em relação ao conhecimento interno à firma, é preciso atenção, pois há muitas informações que se perdem dentro das organizações por não haver ações destinadas a compreender as aptidões, percepções e afinidades de quem interage no funcionamento da empresa. De outro modo, temse aceito que não basta apenas buscar novos conhecimentos, é básico questionar-se, antes, o que já se sabe até então. Conforme afirma Choo (2003, p.25) 
Existem numerosos relatos de empresas que tiveram que reinventar a roda desnecessariamente, por não serem capazes de localizar o conhecimento especializado que existia em algum lugar dentro da organização. Outro obstáculo ao aprendizado é que as organizações acham difícil desaprender o que aprenderam no passado: reexaminar crenças herdadas e questionar as práticas existentes como as únicas alternativas viáveis.

Assim, as inovações são resultado da combinação de conhecimentos derivados da experiência, ou da busca de novos conhecimentos (TIDD; BESSANT, 2015), o que nos remete para o valor de saber o que se conhece em uma organização. Em outras palavras, muito conhecimento pode ter sido acumulado nos indivíduos, mas a falta de gestão desses conhecimentos dispersos pode torná-los ineficazes à medida que não são combinados para gerar soluções ou mesmo para entender os problemas das firmas.

O conjunto de possibilidades de inovações derivadas dessa combinação de conhecimentos não está restrita às tradicionais análises de inovações tecnológicas. Valem as organizacionais, voltadas a diferentes práticas de mercado, e outras muito mais adequadas ao objeto de estudo das pequenas empresas.

Desmistificando a inovação como algo que requer muita tecnologia e investimento, utiliza-se, neste artigo, o conceito de inovação como:

\begin{abstract}
Algo novo que agregue valor social ou riqueza. Muito mais do que um novo produto, algo de inovador pode estar por trás de tecnologias novas, novos processos operacionais, novas práticas mercadológicas, pequenas mudanças, adaptações, enfim, novidades que, de um modo ou de outro, gerem um ganho para quem as pôs em prática. Em termos econômicos - e para que fique bem claro: que gere lucro (TIDD; BESSANT; PAVITT, 2008, p. 9).
\end{abstract}

Deste modo, inovação é um processo que, ainda que guarde as características típicas de incerteza sobre seus resultados, pode ser potencializada por esforços de estruturação na organização voltados às práticas de gestão dos conhecimentos capazes de orientar mudanças, melhorando, assim, a capacidade de reconhecer oportunidades de aprendizado externo e, consequentemente, de desempenho e competitividade.

\title{
APROVEITANDO-SE DO LOCAL: JOINVILLE COMO ESPAÇO DE APROVEITAMENTO DE EXTERNALIDADES
}

Esta subseção apresenta Joinville como um local capaz de gerar grandes externalidades de conhecimento a seus habitantes. Maior cidade de Santa Catarina, Joinville é um polo industrial cuja formação foi orientada pela busca de conhecimento e de recursos 
externos de grandes empresas locais. Conforme estudo realizado por Rocha (1994, p. 89-90), em Joinville "as indústrias, desde o início de suas atividades, buscaram contatos com a Europa (Alemanha, principalmente) para aquisição de matérias-primas, equipamentos, mão de obra qualificada, formação profissional dos proprietários e descendentes". Portanto, essa busca orientou a formação industrial da cidade e, por ser exemplo de virtuosidade, provavelmente tenha influenciado a percepção dos indivíduos locais sobre o valor de superar obstáculos por meio da busca de conhecimentos.

Do ponto de vista da institucionalidade formal, um conjunto de organizações de apoio à busca de conhecimentos se faz presente no território e, certamente, influencia as buscas das empresas. Entre elas o CDL, Clube de Diretores Lojistas de Joinville, desde 1965; a Associação Empresarial de Joinville - ACIJ, de 1991; a associação de Joinville e Região de Pequenas, Micro e Médias Empresas - AJORPEME, de 1984, e o próprio Sebrae, presente na cidade desde 1993, que, atualmente, realiza em torno de 8 mil atendimentos por ano, de acordo com entrevista dada pelo seu Coordenador Regional Norte/SC, Jaime Dias Junior. Essas entidades, além de fornecerem atendimento, contam com núcleos empresariais, realizam cursos, palestras e eventos, como é o caso do Empretec, capacitação realizada exclusivamente pelo Sebrae, com metodologia da Organização das Nações Unidas, que objetiva desenvolver características empreendedoras no gestor.

Um exemplo de importante fonte de informação para os processos de inovação dos empresários de Joinville e região é a Feira do Empreendedor, realizada pelo Sebrae, que envolve atendimentos gratuitos e especializados para o público empreendedor, além da realização de palestras e oficinas. Outro exemplo é a realização anual da Expogestão, evento que possibilita a troca de experiências entre os líderes empresariais, a fim de atualizar tendências, oportunizar relacionamentos e unir o pensamento à prática da gestão empresarial. Há também a Exposuper, organizada pela ACATS (Associação Catarinense de Supermercados), a Feira Mundial de Construtores de Moldes e Ferramentas, Design e Desenvolvimento de Produtos - Euromold, que ocorre paralelamente à Feira e Congresso de Integração da Tecnologia do Plástico - Interplast.

Adicionalmente, importante ressaltar a presença de universidades na cidade, como UDESC - Universidade do Estado de Santa Catarina; Univille - Universidade da Região de Joinville; UFSC - Universidade Federal de Santa Catarina; e UniSociesc - Universidade Sociedade Educacional de Santa Catarina. Todas contam com empresas juniores e realizam pesquisa e oferecem serviços à comunidade empresarial. A renovação institucional é 
frequente, sugerindo adaptação ao ambiente mutante de transformações tecnológicas e organizacionais. Exemplo é a "Sustentare" Escola de Negócios, que, em parceria com as entidades representativas citadas no início da subseção, busca formar profissionais para atuação proativa na gestão e operacionalização de projetos seus ou de outras empresas.

A presença desse conjunto significativo de agentes externos, combinada a um ambiente de valorização das iniciativas individuais, pode influenciar a capacidade competitiva da região. Assim, de acordo com Choo (2003), "a organização que desenvolve desde cedo a percepção da influência do ambiente tem uma vantagem competitiva". Contudo, muitas vezes a presença de externalidades não significa que as empresas sejam capazes de aproveitá-las. A subseção seguinte mostra como o Programa ALI pode funcionar como importante potencializador dessa percepção.

\section{PROGRAMA AGENTE LOCAL DE INOVAÇÃO - INCENTIVO ADICIONAL À CULTURA DA INOVAÇÃO EM JOINVILLE}

Esta subseção tem por objetivo apresentar o Programa ALI como mais uma fonte de informação ao pequeno empresário, abordando também a metodologia utilizada no programa e a ambiência inovadora como forma de mensurar o contato do empresário com o conhecimento externo e interno.

O Sebrae criou, em parceria com o Conselho Nacional de Desenvolvimento Científico e Tecnológico (CNPq), o Programa ALI, que, segundo seu Manual de Capacitação (SEBRAE, 2015), "tem por objetivo promover a prática continuada de ações de inovação nas empresas de pequeno porte, por meio de uma orientação proativa e personalizada". Mediante este programa, cada agente local de inovação (ALI) atende a, pelo menos, 40 pequenas empresas durante 30 meses, e busca levar o empresário a despertar sua percepção sobre inovações que possam ser realizadas na empresa.

Todo o processo de atuação do ALI é orientado por uma metodologia em que, inicialmente, realiza a aplicação de dois diagnósticos: o MPE Brasil, utilizado para diagnosticar o atual estágio da gestão da empresa (BRASIL, 2015, p. 5) e o Radar de Inovação, que busca as oportunidades de inovação existentes para que a empresa se torne uma inovadora sistêmica, ou seja, que a inovação seja prática constante da empresa. Esses diagnósticos permitiram a construção da Matriz SWOT (Strengths/Forças, Weaknesses/Fraquezas, Opportunities/Oportunidades e Threats/Ameaças), que objetiva olhar para o cenário interno e externo da empresa. A sequência é a elaboração de um plano de ação 
(PA) com, no mínimo, cinco ações, de inovação e de gestão, a serem executadas pelos empresários e acompanhadas mensalmente pelos agentes. Estas ações têm por objetivo atacar, por meio de inovações, os pontos que podem ser melhorados na empresa e, assim, ajudar na implementação de uma cultura de inovação empresarial.

A sensibilização para participar do programa é realizada pelo ALI. Note-se disso que a presença do Programa ALI no local incita as empresas a absorverem novas práticas, e mesmo a pensarem sobre suas próprias forças e debilidades. Não raro, isso leva a se tornarem rotina as reuniões de equipe, por exemplo, fazendo com que os conhecimentos dos indivíduos fluam dentro da organização. Assim, o aproveitamento de economias externas pela empresa é causado pela ação externa a ela, ou seja, o programa elaborado por instituição presente no local.

Nesse processo, é notável que alguns empresários relutam para implementar algumas ações, mesmo tendo percebido que estas podem ser importantes para melhorar a produtividade da empresa. Isso deve ser reconhecido como uma certa forma de inércia, compreensível na atividade inovadora, já que não há garantias, a priori, de que o esforço gerará melhor resultado.

\section{METODOLOGIA E BASE DE DADOS}

A ferramenta utilizada neste artigo para obtenção dos dados na pesquisa de campo é conhecida como Radar de Inovação. As 12 dimensões do processo de inovação, elencadas por Sawhney, Wolcott e Arroniz (2006), orientaram o trabalho de Bachmann e Destefani (2008) para elaborar essa ferramenta. Esses autores adicionaram, ainda, a dimensão da ambiência inovadora. Assim, o Radar da Inovação objetiva estimar a maturidade do processo de inovação das pequenas empresas, levando em conta as seguintes 13 dimensões da inovação: Oferta, Plataforma, Marca, Clientes, Soluções, Relacionamento, Agregação de Valor, Processos, Organização, Cadeia de Fornecimento, Presença, Rede e Ambiência Inovadora, explicadas no quadro abaixo, com informações adaptadas do artigo de Sawhney, Wolcott e Arroniz (2006). 
Quadro 1 - Definição das dimensões da inovação

\begin{tabular}{|c|c|}
\hline DIMENSÃO & DESCRIÇÃ̃O \\
\hline Oferta & $\begin{array}{l}\text { As firmas devem desenvolver e ofertar produtos ou serviços } \\
\text { inovadores }\end{array}$ \\
\hline Plataforma & $\begin{array}{l}\text { Trata-se de conjunto de componentes comuns, métodos de montagem } \\
\text { ou tecnologias que é utilizado para desenvolver um portfólio de } \\
\text { produtos ou serviços. }\end{array}$ \\
\hline Soluções & $\begin{array}{l}\text { Pode-se compreender que a solução deve ser customizada. Pode ser } \\
\text { uma combinação integrada de produtos, serviços e informações que } \\
\text { resolvem um problema para o cliente. Portanto, a solução inovadora } \\
\text { gera valor para os clientes, através da amplitude e profundidade de } \\
\text { diferentes elementos. }\end{array}$ \\
\hline Clientes & $\begin{array}{l}\text { São os indivíduos ou organizações que consomem os serviços ou } \\
\text { produtos ofertados pela firma. Nesta dimensão, para inovar a firma } \\
\text { precisa conseguir novos clientes, ou demandas não atendidas devem } \\
\text { ser supridas. }\end{array}$ \\
\hline $\begin{array}{l}\text { Experiência do } \\
\text { cliente/Relacionamento }\end{array}$ & $\begin{array}{l}\text { Perpassa em rever como a firma agrega valor aos seus produtos e/ou } \\
\text { serviços. Para inovar nesta dimensão, a firma pode se utilizar de } \\
\text { fluxos de receitas inexploradas por meio da adequação do sistema de } \\
\text { precificação e ampliando sua habilidade para capturar valor mediante } \\
\text { interações com clientes e parceiros. }\end{array}$ \\
\hline Processos & $\begin{array}{l}\text { Consiste no desenho utilizado para a gestão das operações internas. A } \\
\text { inovação nesta dimensão se dá por meio da redefinição da } \\
\text { configuração desses processos para torná-los mais eficientes, } \\
\text { aumentar a qualidade ou agilizar o tempo do ciclo. }\end{array}$ \\
\hline Organização & $\begin{array}{l}\text { Trata-se de como a empresa se estrutura, seus membros e o papel } \\
\text { desempenhado pelos colaboradores. Nesta dimensão, a inovação } \\
\text { abrange repensar o escopo das atividades da firma e redefinir as } \\
\text { responsabilidades dos seus colaboradores. }\end{array}$ \\
\hline Cadeia de suprimentos & $\begin{array}{l}\text { Rever as fontes de abastecimento e os prazos de entrega. Para renovar, } \\
\text { a empresa pode simplificar o fluxo de informação por meio da cadeia } \\
\text { de suprimentos, mudar a estrutura ou aumentar a colaboração entre } \\
\text { seus participantes. }\end{array}$ \\
\hline Marca & $\begin{array}{l}\text { Caracteriza-se por símbolos, palavras ou qualquer comunicação que } \\
\text { transmita e represente o produto ou serviço ao usuário. Neste sentido, } \\
\text { pode-se inovar impulsionando uma marca em novos domínios. }\end{array}$ \\
\hline
\end{tabular}




\begin{tabular}{|c|l|}
\hline Presença & $\begin{array}{l}\text { Esta dimensão entende-se como os canais de distribuição que a firma } \\
\text { usa para ofertar seus produtos e/ou serviços no mercado e, ainda, o } \\
\text { próprio lugar empregado para a venda ou utilização dos } \\
\text { produtos/serviços pelos consumidores. Pode-se inovar criando canais } \\
\text { de distribuição ou pontos inovadores de presença. }\end{array}$ \\
\hline Rede & $\begin{array}{l}\text { Nesta dimensão, pode-se inovar integrando-se a oferta a de um centro } \\
\text { de inteligência para formação de rede e de novas interações com } \\
\text { parceiros. }\end{array}$ \\
\hline Agregação de valor & $\begin{array}{l}\text { Consiste em adotar meios para recuperar parte do valor criado pela } \\
\text { empresa. Visa a encontrar fluxos de receita não explorados, a } \\
\text { desenvolver novos sistemas de preço, a buscar valor no processo das } \\
\text { interações com clientes e parceiros. }\end{array}$ \\
\hline Ambiência Inovadora & $\begin{array}{l}\text { Inclui o ambiente interno da organização; o clima organizacional deve } \\
\text { ser propício à inovação. }\end{array}$ \\
\hline
\end{tabular}

Fonte: Adaptação de Sawhney, Wolcott e Arroniz (2006); Bachmann e Destefani (2008).

Em cada dimensão são feitas algumas perguntas, que recebem score 1 (pouco ou nada inovador), 3 (inovador ocasional) e 5 (inovador sistêmico). O grau de inovação tem por objetivo estimar um grau de maturidade da inovação nas pequenas empresas, e é mensurado pela média ponderada das respostas, tendo a dimensão ambiência inovadora peso 2 , "devido à sua importância para a implantação efetiva do processo de gestão da inovação". (BACHMANN \& ASSOCIADOS, 2014, p. 15).

$\mathrm{Na}$ ambiência inovadora, foco deste artigo, há 7 perguntas, que procuram saber se a organização busca (I) fontes externas de conhecimento como consultorias ou apoio de entidades e universidades; (II) em eventos, associações técnicas e empresariais; (III) se, de alguma forma, adquire conhecimento com concorrentes, fornecedores ou clientes; (IV) se paga taxas ou royalties por invenções patenteadas ou absorve know-how e competências; (V) se tem patente registrada (pergunta realizada apenas se a empresa for indústria); (VI) ou, ainda, se já utilizou de financiamento subsidiado às inovações; (VII) e se conta com alguma forma de coletar ideias dos colaboradores.

Este estudo foca nas informações conseguidas através da dimensão ambiência inovadora, por compreender que "um clima organizacional propício à inovação é pré-requisito importante para uma empresa inovadora" (BACHMANN e DESTEFANI, 2008, p. 9). Ou seja, estimular e engajar as pessoas envolvidas para que busquem e troquem informação, que explorem o que sabem, que desenvolvam mais conhecimentos e despertem habilidades. Pois 
essa troca com o ambiente, tanto interno quanto externo, é essencial para o processo inovador. A escolha da dimensão foi feita também pela aquisição e troca de conhecimento ter aparecido constantemente na construção da SWOT com os empresários, que analisa Forças, Fraquezas, Oportunidades e Ameaças da empresa, configurando importante oportunidade percebida por estes. Portanto, a SWOT é o momento em que o empresário se posiciona a respeito do cenário interno e externo da empresa.

Para este artigo foram levantados dados de 20 empresas atendidas no Programa ALI, na região norte de Joinville. O primeiro levantamento foi iniciado no começo do programa, em novembro de 2015; o segundo, coletado entre janeiro e agosto de 2017. A pesquisa usa do método descritivo-exploratório, pois descreve os dados para analisá-los, a fim de buscar relação entre as ações implementadas na dimensão ambiência inovadora e seu possível impacto nas outras dimensões do radar. Foram elencados dois casos para exemplificar os resultados obtidos nas organizações quando há busca por conhecimento.

Os resultados dessa pesquisa são avaliados de forma qualitativa, uma vez que não há tratamento estatístico que trace relações entre as variáveis, sendo relatadas ações inovadoras de duas empresas para exemplificar o impacto da busca por informações, além da evolução do Radar de Inovação das empresas analisadas.

A pesquisa utiliza os dados obtidos através do questionário Radar de Inovação. As informações que o preenchem foram conseguidas dentro das empresas, em reunião com os empresários, às vezes com funcionários também, e evidências foram coletadas sempre que possível.

Considerando que a empresa passa do ciclo 0 (C0) para o ciclo 1 (C1) quando conclui pelo menos 3 ações do PA, as empresas que embasam essa pesquisa foram as 20 primeiras a passar do C0 para o C1. Trata-se, portanto, de amostra não aleatória. Dentre estas, há empresas de serviço, comércio e indústria, com atuação em diferentes áreas, como restaurante, panificadora, usinagem, material de construção, pizzaria, bar etc. Como todas elas faturam entre R\$ 360 mil e R\$ 3,6 milhões ao ano, enquadram-se, portanto, como pequena empresa.

Foi realizado gráfico comparativo do $\mathrm{C} 0$ e $\mathrm{C} 1$ utilizando a média dos resultados obtidos em cada dimensão e no grau geral de inovação pelas 20 empresas. Depois há apresentação de duas empresas que melhoraram o score de outras dimensões por meio de ações na ambiência inovadora. Para ilustrar esse ponto, são apresentados os radares de cada empresa. 


\section{APRESENTAÇÃO E ANÁLISE DOS RESULTADOS}

\section{A evolução da atividade inovadora global}

Nesta subseção, serão apresentados e analisados os gráficos comparativos entre o C0 e $\mathrm{C} 1$, que sintetizam os resultados das empresas analisadas.

O gráfico abaixo, em formato de radar, compara a média do resultado obtido no radar de inovação nos ciclos $\mathrm{C} 0$ e $\mathrm{C} 1$ das 20 empresas analisadas. Houve crescimento em todas as dimensões. Esse impacto reflete ações estimuladas pelo programa Agente Local de Inovação, ainda que nem toda mudança derive do programa.

Gráfico 1 - Comparação da média do Grau de Inovação C0 e C1 por dimensão

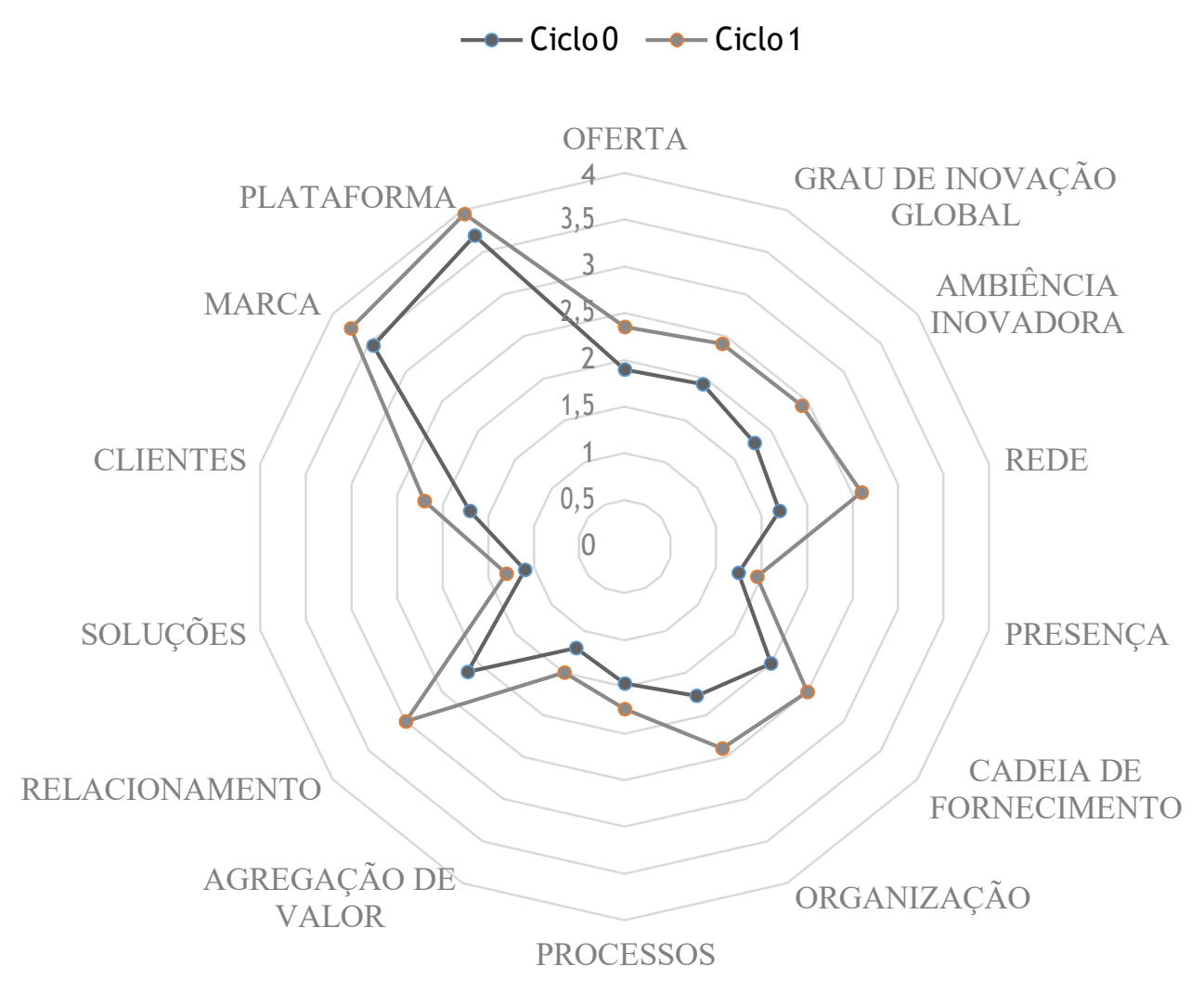

Fonte: Elaboração própria com base na pesquisa de campo.

A experiência de campo permite dizer que uma das ações de maior impacto a esse crescimento foi a institucionalização das reuniões periódicas voltadas à intensificação dos fluxos de conhecimentos dos colaboradores, ação mensurada na dimensão "ambiência 
inovadora". Das 20 empresas analisadas, apenas 3 não implementaram a ação, ainda que todas tenham reconhecido sua importância. É fator contrário à sua realização a necessidade de um consenso entre os sócios e o esforço para encontrar um pequeno espaço de tempo para que as reuniões aconteçam. Ocorre que alguns colaboradores relutam em sua implantação, o que é o primeiro indício de que fazê-lo depende de certa capacidade interna. Em outras palavras, é preciso mudar a estrutura e não apenas a estratégia (intenção), algo significativamente diferente, como mostrou Nelson (2001).

Porém os resultados da melhora no fluxo de informações foram percebidos por todas as empresas que realizaram a ação. Os benefícios foram relatados de formas diferentes; algumas, inclusive, usaram novas ferramentas de tecnologia de informação, como o Design Thinking. Um exemplo do resultado foi uma panificadora em que a empresária passou a realizar as reuniões semanalmente, o que tem levado a pequenas mudanças com alta frequência temporal, como a simples sinalização interna da panificadora, indicando a existência de um espaço superior, antes não utilizado por ser desconhecido pelos clientes. E a forma de alocação de produtos na vitrine, que resultou em um atendimento mais rápido, já que se tornou desnecessário que o cliente perguntasse o que era cada produto, diminuindo filas e consequentes transtornos. Note que a realização das reuniões, ação voltada à elevação dos índices da dimensão de ambiência inovadora, impactou outras dimensões como a de relacionamentos, pelo estreitamento da relação com clientes propiciada pela melhora na vitrine.

Interessante relatar que essa empresária é uma das líderes de um grupo de panificadoras de Joinville e uma das responsáveis pela organização do "Festival de Cucas", criado recentemente, mas que já se tornou um sucesso na região. Esse evento tem impacto direto na empresa, que durante semanas disponibiliza, na panificadora, as cucas prediletas dos clientes, aumentando as vendas. Desse modo, a percepção dos líderes de panificação da cidade, sua união e proatividade possibilitaram um evento, agora incluído no calendário municipal, valorizando a tradição e a história locais.

Nesse caso, foi a comunicação proativa o elemento que abriu as portas para novas ideias geradoras de resultados para os empresários envolvidos, pois assim foi possível compartilhar suas dificuldades, criando soluções coletivas que distribuíram deveres e responsabilidades.

O reconhecimento dos benefícios do engajamento em ações coletivas explica a alta frequência de orientação estratégica das empresas locais em torno da participação em 
atividades externas à empresa. As entrevistas de campo revelaram que um dos elementos mais valorizados pelos empresários tem sido, exatamente, o aprendizado pela troca de experiências entre os participantes. Isso mostra a potência do programa como mecanismo de fluxo de conhecimentos, ou seja, ao aproveitamento das externalidades econômicas locacionais.

\section{IMPACTO DAS AÇÕES IMPLEMENTADAS:}

\section{Exemplos virtuosos da busca por conhecimentos externos aos muros das empresas}

Nesta subseção, será apresentado o caso de duas empresas atendidas, objetos da política do Sebrae de estímulo à atividade inovadora por meio do Programa ALI, como forma de exemplificar a capacidade do programa de impulsionar o aproveitamento de externalidades locacionais de conhecimento, de forma a impactar a capacidade inovadora observável em diferentes dimensões do Radar da Inovação.

O primeiro caso selecionado foi o de uma usinagem e ferramentaria, Empresa 1. Nela, o empresário participou do Empretec por sugestão da ALI. O curso moldou seu comportamento empreendedor e desenvolveu a percepção para a gestão de processos que apoiam a introdução de inovações. A estratégia da empresa mudou significativamente, o que se pode verificar pela elaboração de um novo plano de ação. Entre as ações estavam metas de produtividade dos colaboradores, plano de capacitações e participação no núcleo setorial de ferramentaria da Associação Comercial de Joinville - ACIJ. Notável que o movimento inicial de busca de conhecimentos fora dos muros da firma, via participação no Empretec, tenha gerado novas investidas, tais como participação no núcleo setorial de ferramentaria da ACIJ. Daí nossa compreensão de que a atuação do Sebrae, via Programa ALI, esteja promovendo a disseminação de cultura empresarial mais adequada ao aproveitamento das economias externas potenciais de certos locais.

Corrobora essa percepção o fato de a participação do mesmo empresário, em uma palestra de liderança, também sugerida pela ALI, na Sustentare Escola de Negócios, ter resultado na reorganização das atividades da equipe, por meio da descentralização das funções. Essa reorganização resultou na diminuição de "peças mortas" por erros e garantiu que as tarefas fossem executadas com maior eficiência. Com isso, o empresário passou a ter mais tempo para buscar novos negócios/clientes! Essas mudanças melhoraram a dimensão organização do Radar.

No gráfico abaixo é possível perceber a evolução da Empresa 1: 
Gráfico 2 - Radar de Inovação C0 e C1, Empresa 1

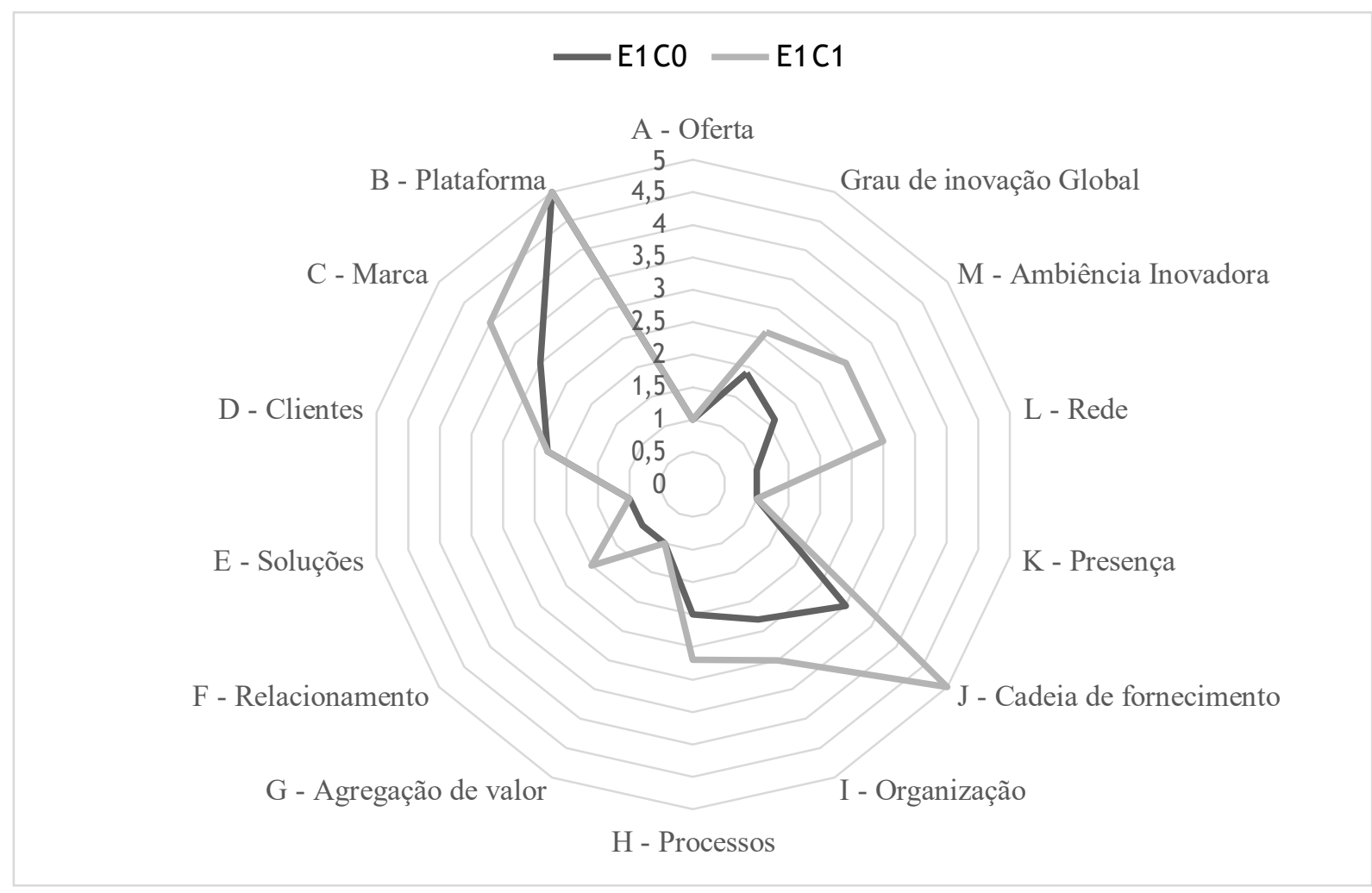

Fonte: Elaboração própria com base na pesquisa de campo.

Importante pontuar que há também desvantagens na participação em atividades geradoras de economias. Há casos de deseconomias realizadas que, por vezes, são considerados pelos empresários e ajudam a explicar certas restrições ao aproveitamento dessas economias potenciais. Outra empresa de usinagem que também passou a participar do Núcleo Setorial da ACIJ relatou ter perdido um importante funcionário exatamente em uma atividade do Núcleo Setorial, o que fez o empresário restringir a participação da firma.

O relato do segundo caso é o de uma produtora e delicatessen de produtos livres de glúten e lactose, Empresa 2. Os produtos são destinados a pessoas com alergias e restrições alimentares, portanto, é preciso um enorme zelo na produção, para garantir sua confiabilidade. Sendo assim, comunicar ao cliente que os produtos estão de acordo com as exigências é algo necessário. Porém, a embalagem da empresa não conseguia fazer essa comunicação. Foi contratado, então, juntamente com o Sebrae e o Programa ALI, o Sebraetec, para fornecer consultoria tecnológica especializada em design, com o intuito de buscar uma embalagem econômica, prática e que comunicasse os valores da organização. A mudança, orientada por consultor técnico, sendo, portanto, diagnosticada na dimensão ambiência inovadora, impactou a dimensão oferta do radar, ao mudar a estética ou funcionalidade do produto. 
Mais importante aos objetivos deste artigo foi que a orientação técnica estimulou a busca da empresa por feedbacks dos clientes em relação ao produto. Disso, notou-se a necessidade de modificar características do produto para atender a aspectos de uma demanda contemporânea mais sofisticada em relação à qualidade do produto. Daí que a empresa também tenha se apoiado em conhecimento acadêmico para a substituição de um ingrediente das receitas. Isso envolveu contratação da CONAQ - Empresa Júnior de Engenharia Química e Alimentos da UFSC - para encontrar um substituto da margarina com determinadas características demandadas pela nova receita que procurava atender às exigências dos clientes. No fim do trabalho, foi possível aprimorar a receita, satisfazendo a demanda mais sofisticada, tendo se utilizado de um conjunto relevante de conhecimentos disponíveis no local, mas que, sem o estímulo do programa ALI, teria, possivelmente, permanecido em estado potencial. Esse conjunto de atividades impactou as dimensões organização, clientes e outras do Radar de Inovação, revelando, ao final, uma empresa mais adequada ao ambiente inovador contemporâneo.

Gráfico 2 - Radar de Inovação C0 e C1, Empresa 2

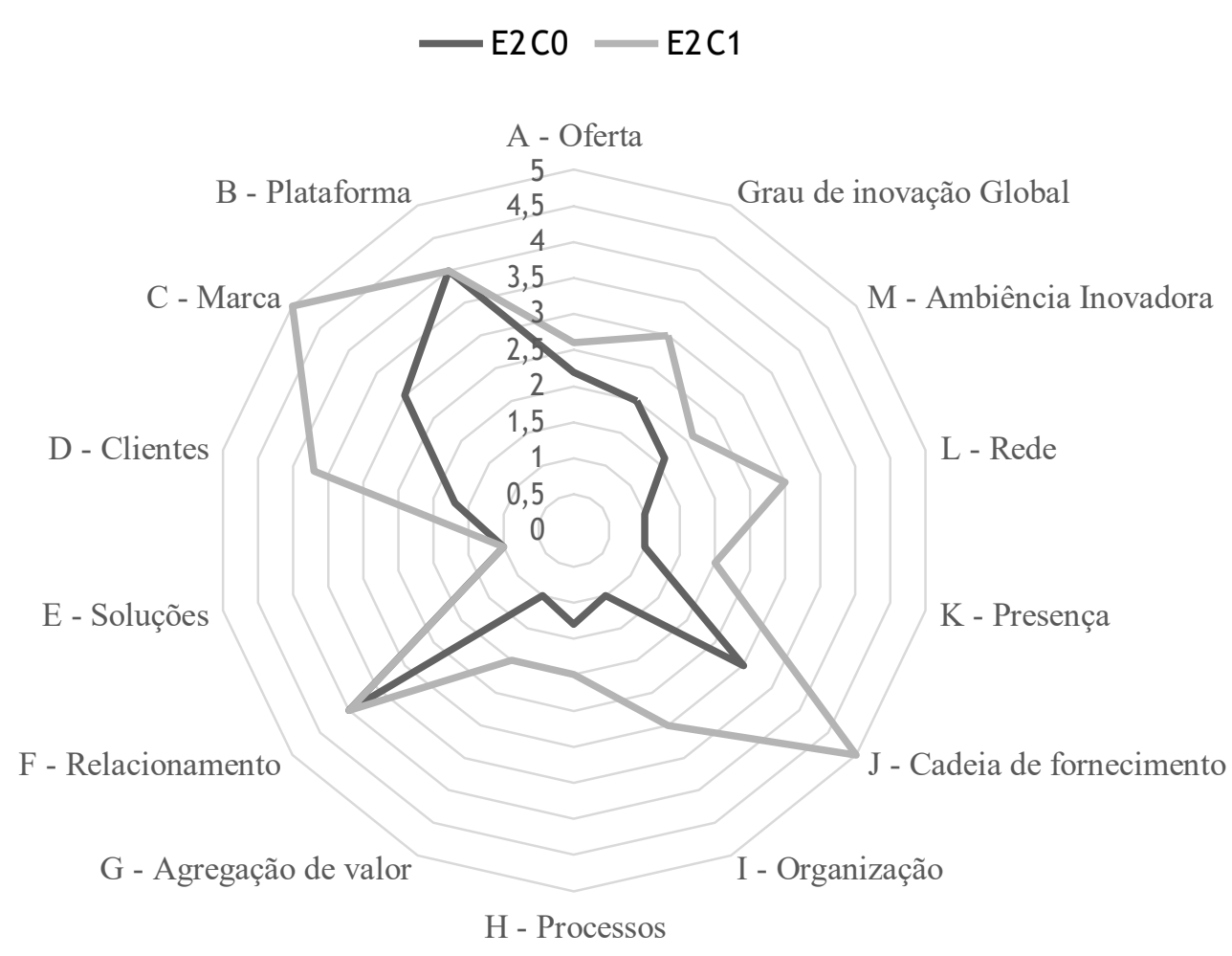

Fonte: Elaboração própria com base na pesquisa de campo. 
Portanto, identificar as possibilidades estratégicas da empresa, seus parceiros e como podem organizar seus colaboradores para realizar seu potencial, parece, em certa medida, ser reflexo do posicionamento que essas empresas assumem diante das fontes de conhecimento e informação a que estão expostas, e, principalmente, das fontes que procuram. Muitas ações advêm de novidades percebidas por atores da organização, pelo contato com outras empresas, inclusive, por concorrentes. Essas ações impactam as empresas e geram um comportamento mais interessado no ambiente em que estão envolvidas. A debilidade, nesse sentido, foi percebida no trabalho de campo, ou seja, nas entrevistas realizadas ainda na execução do projeto ALI por um dos autores deste artigo, já no momento de elaboração da SWOT com os empresários. Era notável a fraqueza da falta de comunicação com os colaboradores, assim como a restrita participação em eventos, palestras, cursos, feiras e mesmo na relação com fornecedores. Isso chamou atenção, considerando-se Joinville o maior polo industrial do Estado de Santa Catarina.

Interessante ressaltar, ainda, que a participação mais ativa dos colaboradores parece motivá-los. Quando foram ouvidos dentro da organização, em geral, deixaram de apenas executar suas tarefas e passaram a se interessar por elas, buscando informações dentro e fora da empresa, para que estas se transformassem em ações efetivas. Para alguns isso significa ser parte efetiva da organização, o que ajuda a explicar um comportamento proativo, capaz de transformar as atividades rotineiras, encontrando soluções que facilitem os processos, aumentem a produtividade, reduzam desperdícios e melhorem a experiência do cliente.

\section{CONCLUSÃO}

Este estudo apresentou o conceito de economias externas, a fim de explorar o ambiente em que as empresas atendidas pelo Programa ALI Joinville estão inseridas, analisando, assim, as vantagens de estar diante de um cenário rico em oportunidades potenciais, mesmo considerando as limitações impostas pela crise aguda que o país atravessa. Pode-se notar que as economias externas são aproveitadas sempre que as empresas estão aptas a fazê-lo. A dimensão ambiência inovadora do Radar da Inovação assume função muito relevante no sentido de permitir a compreensão do grau em que as empresas se encontram em suas atividades internas, as quais propiciam absorção de conhecimentos externos.

O estudo permitiu verificar, ainda, que o estímulo à percepção sobre as oportunidades externas dadas pelo Programa ALI impulsionou o aproveitamento de externalidades 
locacionais, ampliando a qualidade das empresas no que se refere à sua capacidade inovadora, mensurada pelas diversas dimensões do Radar de Inovação. Em outras palavras, o programa foi capaz de estimular a mudança de postura dos empresários diante do arsenal de informações que está disponível no local. Nesse sentido, uma transformação das rotinas da empresa, em prol de uma cultura de inovação, mais voltada para a busca de conhecimentos externos complementares aos internos, parece ser um dos maiores resultados da política do Sebrae.

Finalmente, ao trazer à reflexão o conceito de externalidades locacionais como elemento de significativa influência ao processo inovador, pontuou-se a região de Joinville como fonte de conhecimento, capaz de influenciar mudanças consideráveis às empresas inseridas nesse espaço. Notou-se que vários elementos apoiam a formação do espaço local como fonte de conhecimentos, indo das diversas organizações empresariais ao cenário acadêmico, mas especialmente pela frequência de eventos contemplados pela dinâmica da cidade. Tais recursos das cidades, que certamente servem a empresas industriais voltadas ao desenvolvimento tecnológico, parecem também ser úteis às inovações típicas de empresas de porte muito reduzido e inseridas em segmentos cujos conhecimentos convenientes aos processos de inovação são, em geral, organizacionais e mais elementares do que os tradicionalmente pesquisados.

Pelo menos uma linha de pesquisa emerge desses resultados. Considerando-se o atual contexto de enorme interatividade e de redução ao limite do custo de um conjunto enorme de informações, quais as causas da proximidade geográfica e da dinâmica de grandes cidades ainda parecerem ser tão importantes a empresas cujos conhecimentos relevantes para inovar são relativamente elementares?

\section{REFERÊNCIAS BIBLIOGRÁFICAS}

ACATS, 2017. Disponível em http://www.exposuper.com.br/a-exposuper-2017. Acessado em $13 / 082017$.

ACIJ, 2016. Disponível em http://www.acij.com.br/institucional/show/area/hist-rico. Acessado em 13/082017. 
AJORPEME, 2015. Disponível em http://ajorpeme.com.br/ajorpeme-micro-pequena-mediaempresa/. Acessado em 13/082017.

BACHMANN \& ASSOCIADOS. Atualização dos formulários para determinação do Radar de Inovação do Programa ALI - Relatório Técnico. 2014.

BACHMANN, D. L.; DESTEFANI, J. H. "Metodologia para estimar o grau de inovação nas MPE. Cultura do Empreendedorismo e Inovação”. In: XVIII Seminário Nacional de Parques Tecnológicos e Incubadoras de Empresas. Aracaju, 2008. (Disponível em http://www.bachmann.com.br/website/documents/ArtigoGraudeInovacaonasMPE.pdf, acesso em 10/082017).

BESSANT, J.; TIDD, J.; PAVITT, K. Gestão da inovação. v. 3. Porto Alegre, 2008.

BITTENCOURT, P.F.; CHIARINI, T. RAPINI, M. “Arranjos Produtivos Locais na Dinâmica Global Contemporânea”. Revista Econômica do Nordeste, n. 1, v 48, 2017.

BRASIL, M.P.E. "Prêmio de Competitividade para Micro e Pequenas Empresas". Questionário de Auto-avaliação, 2015.

COHEN, Wesley M.; LEVINTHAL, Daniel A. "Absorptive capacity: A new perspective on learning and innovation”. Administrative science quarterly, v. 35, n. 1, p. 128-152, 1990.

CHOO, C. W. A organização do conhecimento: como as organizações usam a informação para criar significado, construir conhecimento e tomar decisões. Senac São Paulo, 2003.

DE OLIVEIRA, M. F.. Metodologia científica: um manual para a realização de pesquisas em Administração. $2011 . \quad$ (Disponível em https://adm.catalao.ufg.br/up/567/o/Manual_de_metodologia_cientifica__Prof_Maxwell.pdf, acesso em 10/082017).

EXPOGESTÃO, 2017. Disponível em http://www.expogestao.com.br/sobre-a-expogestao/. Acesso em: 13/08/2017.

FREEMAN, C.; SOETE, L.. A economia da inovação industrial. Editora da Unicamp, 2008. 
GARCIA, R.. Economias externas e vantagens competitivas dos produtores em sistemas locais de produção: as visões de Marshall, Krugman e Porter. Ensaios FEE, v. 27, n. 2, 2006.

GIULIANI, E.. "Cluster absorptive capacity: why do some clusters forge ahead and others lag behind?". European urban and regional studies, v. 12, n. 3, p. 269-288, 2005.

IBGE. Contas nacionais trimestrais: indicadores de volume e valores correntes out./dez. 2016. Rio de Janeiro: IBGE, 2017. (Disponível em ftp://ftp.ibge.gov.br/Contas_Nacionais/Contas_Nacionais_Trimestrais/Fasciculo_Indicadores IBGE/pib-vol-val_201604caderno.pdf, acesso em 10/08/2017.

MÉNDEZ, R.. "El territorio de las nuevas economías metropolitanas”. Eure (Santiago), v. 33, n. 100, p. 51-67, 2007.

NELSON, Richard R. "Why do firms differ, and how does it matter?". Strategic Management Journal, v. 12, n. S2, p. 61-74, 1991.

NELSON, R. R.; WINTER, S. G. Uma teoria evolucionária da mudança econômica. Editora Unicamp, 2005.

\section{OECD; DEVELOPMENT. ECONOMIC ANALYSIS; STATISTICS DIVISION. OECD}

Science, Technology and Industry Scoreboard 2003. Canongate US, 2003.

OCDE. MANUAL DE OSLO. Proposta de Diretrizes para Coleta e Interpretação de Dados sobre Inovação Tecnológica. Organização para a Cooperação Econômica e Desenvolvimento - Departamento Estatístico da Comunidade Europeia - FINEP - Financiadora de Estudos e Projetos - texto original de 2005.

PEREZ, C.. A onda atual de mudança tecnológica: Implicações para a reestruturação competitiva e para a reforma institucional nos países em desenvolvimento. Washington: Banco Mundial, 1989.

PEREZ, Carlota. "Technological revolutions and financial capital". Edward Elgar Publishing, 2003.

PNAD, Disponível em http://br.advfn.com/indicadores/pnad/2017. Acesso em 29/08/2017. 
ROCHA, I. O. et al. Industrialização de Joinville (SC): da gênese as exportações. 1994.

Disponível em

https://repositorio.ufsc.br/handle/123456789/76154. Acesso em 10/08/2017.

ROSENBERG, N.. Por dentro da caixa-preta: tecnologia e economia. Unicamp, 2006.

SAWHNEY, M.; WOLCOTT, R. C.; ARRONIZ, I.. "The 12 Different Ways for Companies to Innovate". MIT Sloan Management Review, Spring, p. 75-81, 2006. (Disponível em http://sloanreview.mit.edu/article/the-different-ways-for-companies-to-innovate/, acesso em 10/08/2017).

SIMON, Herbert A. "From substantive to procedural rationality. In: 25 years of economic theory”. Springer, Boston, MA, 1976. p. 65-86.

SEBRAE. Manuais do Curso de Capacitação do Programa Agentes Locais de Inovação. 2015.

SPITHOVEN, A.; CLARYSSE, B.; KNOCKAERT, M.. "Building absorptive capacity to organise inbound open innovation in traditional industries". Technovation, v. 30, n. 2, p. 130$141,2010$.

SUSTENTARE, Escola de Negócios, 2015. Disponível em http://www.sustentare.net/site/institucional/conheca-a-sustentare/. Acesso em 13/08/2017.

TIDD, J.; BESSANT, J.. Gestão da inovação-5. Bookman Editora, 2015.

ZAHRA, S. A.; GEORGE, G.. “Absorptive capacity: A review, reconceptualization, and extension". Academy of Management Review, v. 27, n. 2, p. 185-203, 2002. 